\title{
CUERPOS ENTRE CUERPOS, VIDA DENTRO DE LA VIDA, ENCUENTROS
}

\author{
BODIES BETWEEN BODIES, \\ LIFE WITHIN LIFE, ENCOUNTERS
}

\author{
OMAR FELIPE GIRALDO \\ Universidad Nacional Autónoma de México (UNAM), México \\ omarfgiraldo@gmail.com
}

\section{RESUMEN}

Este artículo pregunta por las posibilidades de lo que somos capaces al reconocernos como cuerpos deambulando que se encuentran con otros cuerpos ¿Qué es lo que podemos? ¿Qué implica una epistemología ambiental que ponga en primer plano la sensibilidad, el cuerpo, lo sentido y los afectos? Comenzamos con una discusión sobre las dicotomías, los monismos y dualismos, para ofrecer luego una propuesta desde las multiplicidades, los cuerpos entre cuerpos, y los encuentros entre alteridades radicales ¿Es posible abrir una vía media que abandone toda dualidad y que evite borrar las diferencias? ¿Podemos imaginar una ética ambiental que parta desde el cuerpo, el universo sensible y los contactos? Aún no sabemos todo el poder que tiene un cuerpo cuando se sabe cómo un cuerpo que habita entre otros cuerpos.

Palabras clave: Epistemología ambiental, Sensibilidad, Ética ambiental.

\section{ABSTRACT}

This article is concerned about the possibilities of what we are able to do once we acknowledge the fact that we are wandering bodies in contact with other bodies. What can we do? What does an environmental epistemology entail once sensitivity, body, meaning and affection are brought to the front? We begin with a discussion on dichotomies, monisms and dualisms, to offer, afterwards, a proposal from multiplicities, bodies between bodies, and encounters between radical alternatives. Is it possible to open a halfway point free from dualities, and, at the same time, respectful of differences? Can we imagine an environmental ethic that starts from the body, the sensible universe and the touch? We are unaware of all the power that a body entail when it is known as a body that dwell among other bodies.

Keywords: Environmental epistemology, Sensitivity, Environmental ethics. 


\section{INTRODUCCIÓN}

La epistemología ambiental ha insistido en que la crisis ambiental es una crisis ontológica, una consecuencia de la forma como entendemos nuestro ser y la relación con el resto de los seres que se deriva de esa misma concepción. En términos muy generales corresponde a una comprensión en la que nos ubicamos en la escala más alta de las manifestaciones del ser, imaginando al resto de los entes como objetos inertes, recursos disponibles a nuestra entera disposición. En la filosofía esta separación del ser humano y el resto de los seres, ha sido atribuida al pensamiento metafísico que se remonta a Platón, y que se consolida en la modernidad con el positivismo cartesiano. Esta tradición ha realizado una separación entre el sujeto y el objeto, la cual parte de la noción según la cual el mundo "es" de cierto modo - un mundo objetivo-, y de ahí se deriva que el conocer consista en que el sujeto se haga una idea que se adecúe de manera fidedigna al objeto. De hecho es posible alcanzar "la verdad" en cuanto más certeramente se represente ese objeto que se desea conocer. Para la epistemología positivista, la existencia de las cosas es independiente del sujeto, $y$, en consecuencia, es posible conocer el mundo "tal cual es". De hecho, entre más distancia exista entre el sujeto conocedor y el objeto conocido, mayor será la objetividad.

El pensamiento ambiental asegura que con esa división constitutiva del pensamiento moderno, por un lado, el ser humano llegó a representarse a sí mismo como centro del mundo, como poseedor de todo cuanto existe a su alrededor, mientras que, por el otro, acabó por concebir lo que él llama "naturaleza" como un objeto inerte, un recurso disponible y una cosa dispuesta a ser manipulada por la ciencia y la técnica (Heidegger, 1996). El pensamiento ambiental también ha asegurado que la ontología moderna no sólo se caracteriza por la separación sujeto/objeto, sino que es un tipo particular de ontología patriarcal caracterizada por otras diadas polares como lo son: mente/ cuerpo, cultura/naturaleza, razón/afectos, civilizado/primitivo, masculino/femenino, secular/sagrado, individuo/comunidad (Plumwood, 2002; 2005). El problema, ha dicho Arturo Escobar (2013), no es tanto que existan los dualismos, pues muchas otras tradiciones desde el taoísmo, el budismo, y buena parte de los pueblos indígenas, en distintos continentes, han basado sus ontologías en dualidades interconectadas bajo el principio de la complementariedad. El problema es que en la modernidad la primera parte de los dualismos -el sujeto, la mente, la cultura, la razón, lo civilizado, lo masculino, lo secular-, se separa y se sitúa en una posición de superioridad frente a la parte subordinada del binarismo - el cuerpo, la naturaleza, los afectos, lo primitivo, lo femenino, lo sagrado- ${ }^{1}$.

Es entonces bien reconocido por el pensamiento crítico que la crisis ambiental no es un problema de carácter geológico o ecológico, sino un entuerto civilizatorio producido por un tipo particular de ontología, generado por el pensamiento ontológico y sus escisiones constitutivas (Leff, 2018). Una crisis o colapso que emerge como consecuencia de una ontología basada en el "yo" moderno y en la creencia de que el mundo está compuesto por muchos "yoes" separados entre sí -la humanidad compuesta por la suma de sus individuos- pero separada de lo demás,

\footnotetext{
${ }^{1}$ En pensamiento ambiental por tal razón, ha dicho Val Plumwood (2002; 2005), no es entonces un tipo de saber enfocado exclusivamente en defender la naturaleza no-humana -las plantas, animales, los ecosistemas-, sino un tipo de ontología política que defiende los aspectos reprimidos de la dualidad: la afectividad, la sensibilidad, la intuición, la espiritualidad, la feminidad, el cuerpo, y todos aquellos atributos asociados con "la naturaleza", ubicados en un nivel de inferioridad, y por tanto susceptibles de ser explotados y dominados.
} 
de los otros seres del mundo -el resto: la naturaleza-. De aquella auto determinación fragmentada, surge una ética del saber que consiste en desocultar la verdad mediante la ciencia para luego intervenir y manipular lo conocido con el auxilio técnico, para vencer la escasez, y cubrir lo que la economía ha dictado como necesario para uno solo de los seres sensibles de la Tierra.

De este diagnóstico de la crisis ambiental surge un coro de voces del pensamiento encaminadas a superar la ontología dualista y caminar hacia otras ontologías conectadas a los entramados de vida. Esa es la base que aglutina a la mayoría de pensadores ambientales, quienes en distintas partes del mundo denuncian la escisión e intentan proponer salidas ontológicas y epistémicas, así como éticas relacionales, ante la devastación que surge como síntoma de la concepción de nuestro ser separado de la naturaleza.

Una de las voces más conocidas es la de Arne Naess (2007) y su propuesta de ética ambiental denominada Ecología Profunda, cuya apuesta consiste en hacer una operación de sutura, borrando la disyunción, proporcionando una solución para ello en términos de la identificación del "yo" con la naturaleza. Para los adherentes a esta ética ambiental, es necesario superar la separación de los seres humanos y la naturaleza, asegurando que no puede existir división ontológica entre dos reinos: el humano y no humano, sino más bien entender el universo como un todo, interconectado y sin fisuras. Los ecólogos profundos sostienen que es necesario remplazar la escisión por un entendimiento holístico, partiendo del hecho de que todo está interrelacionado y es interdependiente con lo demás. Por ello es necesario abandonar la separación y entrar en la unificación, al entender que todo cuanto existe en realidad es "parte de", e indistinguible de lo demás (Fox, 1984). Y es a partir de nuestro autoentendimiento como seres inter-relacionales, y nuestra identificación del "yo" con la totalidad, como es posible que se impulse el cuidado, no por altruismo, ni por un "deber ser" moral, sino porque el cuidado de lo demás hace parte del interés de la propia existencia.

Si quisiéramos hacer una arqueología del holismo en la filosofía occidental, tendríamos que remitirnos al pensamiento de Baruch Spinoza2, quien planteó una vía completamente diferente al dualismo cartesiano. Spinoza (2011) impugnó la idea de que podíamos poner a los seres humanos separados del reino de la naturaleza, como si se tratase de "un imperio dentro de otro imperio" y no como la naturaleza misma. Muy al contrario para él, sólo existe una sola y única substancia absolutamente infinita, y lo que llamamos criaturas, no lo son; son tan sólo modos o formas de existencia de aquella sustancia. Todos los existentes, no somos en realidad seres, sino entes, manera de ser de esa sustancia (Deleuze, 1980). Se trata, sin duda, de una visión que podría ser comparable a la de otras tradiciones como el Taoísmo de Lao Tse, o algunas ontologías de los pueblos ancestrales del Abya Yala3. Por cualquiera de los caminos, estas fuentes han sido buena base para la inspiración de algunos pensadores ambientales, quienes han pretendido superar el dualismo cartesiano, mediante una visión holística del mundo. Entre ellos no sólo están los exponentes de la Ecología Profunda, sino otros autores, entre los cuales

\footnotetext{
Para profundizar la relación entre la ética de Spinoza y la ecología profunda véase Naess (1980).

Para los pueblos Tzeltales de Chiapas, México, por ejemplo, existe la concepción del Ch'ulel, el cual, según López-Intzín es el corazón-alma-espíritu-conciencia que lo anima todo, que lo energiza todo. Según estos pueblos todo ser tiene Ch'ulel: "El ser humano, las plantas, los animales, los minerales, los cerros, los ríos y todo lo que existe en el universo tiene Ch'ulel- ch'ulelal. Por lo tanto todo tiene su propio lenguaje y habla, siente, llora, su corazón piensa" (López-Intzín, 2016: 190).
} 
vale la pena resaltar el pensamiento complejo de Edgar Morin (1986), la trama de la vida de Fritjof Capra (1998), la teoría de Gaia de James Lovelock (2007), el postestructuralismo de Gilles Deleuze y Félix Guattari (2004), o la antropología ambiental de Descola y Pálsson (2001) o Viveiros de Castro (1998).

Este tipo de posturas que buscan la reunificación en un todo orgánico ha sido cuestionado por algunos pensadores, quienes han dado buenos argumentos sobre los peligros que conlleva que el Dualismo ontológico - la separación ser humano y naturaleza- se solucione mediante un Monismo ontológico, es decir, a través de su unificación. Entre los críticos más agudos vale la pena mencionar a la ecofeminista Val Plumwood (2002), quien coincide con los ecólogos profundos, en que es necesario superar los dualismos; de hecho gran parte de su obra trata sistemáticamente sobre ellos. Sin embargo, asegura, no es necesario, ni deseable, tratar de asimilar al Otro, borrando su distinción y diferencia. Según la filósofa australiana para superar el dualismo es necesario mantener un equilibrio entre la continuidad y la diferencia, pues la dialéctica entre la conexión y la alteridad es la clave para una interacción no instrumental. Plumwood sostiene que la pérdida de tensión entre lo diferente y lo semejante ha sido una de las características principales de la historia de la colonización. El proceso siempre ha sido el mismo: devorar al otro, negar su diferencia e incorporarlo en un proceso totalizador.

Plummwod (2002) sostiene que existe una enconada arrogancia cuando no se respetan los límites, ni se reconocen las diferencias, que, en últimas, son la base del respeto. Claro que se debe reconocer la continuidad humana con el mundo natural, asevera, pero también reconocer su distinción, e incluso su independencia de nosotros, y la distinción de las necesidades de la naturaleza con respecto a las nuestras. Para Plummwod no es útil, y ni siquiera necesario, hacer una fusión para superar las dicotomías, pues la ética del cuidado que promueve el ecofeminismo requiere también tomar distancia y reconocer la diferencia, de modo que al otro no se le vea como una proyección del sí mismo. Su propuesta consiste entonces, en avanzar hacia un tipo de ética que permita tanto la continuidad como la diferencia, y evite la abstracción, la disolución, y el desdibujamiento de la distinción entre seres humanos y naturaleza.

Por su parte, el gran filósofo ambiental mexicano, Enrique Leff (2004, cap. 2) también ha hecho una crítica al Monismo ontológico, aunque en diálogo con el ecoanarquista Murray Bookchin (1990), quien desde otra perspectiva ha propuesto la combinación entre el orden ecológico y el orden sociocultural. Para Leff es imposible aspirar a una totalidad unificante que funda en una mismidad la materialidad del mundo y lo simbólico. Y ello ocurre porque no puede desconocerse que el orden simbólico, a través de las significaciones, el lenguaje y la organización de la cultura, tejen la vida del ser humano, tanto en sus relaciones sociales como de poder, y que ellas de ninguna manera pueden subsumirse dentro de un orden unificante. Leff abreva en Lacan para decir que no hay nada menos natural que el sujeto y la conciencia, el deseo y el orden simbólico. Por esta razón es inútil intentar hacer una fusión y confusión entre ambos órdenes; es imposible disolver la separación entre lo Real y lo simbólico, y aspirar a una visión totalizadora y ominicomprensiva del mundo.

Recordemos que el psicoanálisis de orientación lacaniana -en el que se asienta parte de la obra de Leff-, sostiene que lo humano no tiene nada que ver con el orden natural porque obedece a reglas distintas a las de la 
naturaleza. Johnston (2010) ha llegado a decir que habitamos en el plano de la anti-physis, un lugar que llamamos "cultura" (Ruíz, 2008). El sujeto, tiene que arreglárselas desde esa constitución subjetiva, es decir, desde el universo simbólico "no-natural" para encontrarse con lo Real de la physis. Para ello construye significantes en el lenguaje cuya función es mediar entre él y lo Real. El sujeto no tiene más remedio que crear significantes para crear sentido de la vida, pues es ahí donde encuentra su guarida. Cuando enunciamos la palabra "Naturaleza" o "Madre Tierra", no estamos allegando en sí mismo al mundo Real, sino ello es más bien una designación ${ }^{4}$, un significante que sirve para producir algo de historicidad en el ser humano. Para Lacan existe una escisión imposible de superar, y por tanto necesitamos de la estructura simbólica para relacionarnos con el mundo (Ruíz, 2018).

De esta explicación psicoanalítica que reivindica la inevitable escisión del sujeto de la naturaleza, es que Leff se basa para cuestionar las propuestas encaminadas a que el divorcio entre sociedad y naturaleza pueda resolverse por la ecologización del orden social. Leff coincide con Plumwwod en que es necesaria una ontología de la diferencia y una ética de la otredad, negando la escisión cartesiana, por supuesto, pero aceptando que lo que hay es dialéctica: un juego de relaciones entre la cultura y la naturaleza; una hibridación ontológica entre distintos órdenes diferenciados, el primero explicado desde una perspectiva simbólica, mientras el segundo desde la termodinámica como la condición necesaria para la reproducción de la vida en la Tierra. La propuesta de Leff (2014:254) es entonces no hacer "un forzamiento monista de la diferencia

En la sabiduría oriental hay una frase del monje budista Nagarjuna (2004) que sintetiza maravillosamente esta idea: "Si hubiera identidad entre la palabra y su objeto, el término "fuego" quemaría en la boca". ontológica", sino rencausar el pensamiento hacia la inmanencia de la vida, hacia las condiciones ecológicas del planeta, de modo que pueda fundarse "una nueva coherencia entre lo Real y lo Simbólico".

Aunque ambos autores parten de la fragmentación metafísica de la cultura occidental como el origen de la crisis ambiental, concuerdan en afirmar que la vía del Monismo ontológico no está libre de problemas. Sustentan con buenos argumentos lo inadecuado que puede llegar a ser la anulación de la diferencia de la otredad, como la del orden simbólico propio del animal humano.

En una vía intermedia va la propuesta del filósofo ambiental colombiano Augusto Ángel Maya (1996), quien anida en el pensamiento darwiniano y spinoziano. Al igual que Lacan, Plumwood y Leff, sostiene que tanto el ecosistema como la cultura tienen su propio orden. De acuerdo con Ángel Maya las características de la especie humana evolucionaron por un camino distinto al de las plantas y los animales, y esa ruta llevó a esta particular especie a ser desterrada para siempre del paraíso ecosistémico, a convertirse en una criatura simbólica. Sin embargo, Ángel Maya plantea subrepticiamente un diálogo entre Spinoza y Darwin al afirmar que la cultura, en cuando forma adaptativa, hace parte de la naturaleza. Aunque ya no pertenezcamos al orden ecosistémico, ni sigamos sus leyes, ni pertenezcamos a algún nicho ecológico, seguimos siendo parte de la naturaleza: emergencia de una sola sustancia inmanente de la cual es imposible separarnos. La cultura es una prolongación de la evolución, asegura, "un hecho tan natural como la evolución biológica". Ángel Maya es contundente al afirmar: "Es la naturaleza la que se convierte en cultura. La cultura no constituye una intromisión extraña en el orden de la naturaleza. Es una fase de la misma naturaleza" (1996:58). Con esa explicación 
Ángel Maya evita la discusión lacaniana sobre si la cultura es parte o no de la naturaleza, pero al mismo tiempo mantiene la distinción entre cada uno de los órdenes.

Tenemos pues a Plumwood, Leff y Ángel Maya, defendiendo la idea de la dialéctica entre ambos órdenes: la cultura y los ecosistemas, lo simbólico y lo Real, aunque difiriendo -en el caso de los filósofos latinoamericanos- si la cultura hace parte del dominio natural. Más allá de zanjar este debate -el cual diferiría si lo hacemos desde la perspectiva evolutiva o el postestructuralismo, o bien, desde la lingüística o el psicoanálisis lacaniano- creo que ambas posturas, aunque contradictorias, aportan elementos muy importantes para la constitución de una epistemología ambiental. No es mi intención hacer una síntesis conciliadora entre ambas, lo cual no es posible ni deseable, pero lo que sí pienso es que es necesario tomar en serio el argumento de Leff y Ángel Maya, según el cual el área de intervención del pensamiento ambiental debe darse en el enjambre simbólico, en el lenguaje y sus procesos de significación, y desde ahí crear otros procesos de simbolización, para conseguir una ontología de la diferencia y una ética de la otredad; pero, por el otro lado, estimo necesario hacerlo desde el campo de la interrelación, la interdependencia, y la continuidad entre todas las manifestaciones y expresiones del universo.

Para hacer este fundamental trabajo creo que es insuficiente plantear el problema desde dos órdenes: el de la cultura y el de la naturaleza. Aunque siempre debemos tener muy en cuenta las particularidades humanas, sus enjambres simbólicos, el lenguaje, y sus procesos de significación, como han insistido Lacan o Leff, opino que es insuficiente mantener el dualismo ontológico, así sea en términos dialécticos o correspondencia, complementariedad, reciprocidad, y no-jeraquía, en la medida en que seguimos pensando el problema epistémico de la crisis ambiental desde dos dominios: lo humano y lo no-humano.

A lo que me refiero es que no deberíamos seguir intentando solucionar las escisiones metafísicas entre las personas y el resto de los seres, con la misma categoría de pares para hacer la relación; es decir, la invitación es a no plantear el problema como un asunto de articulación entre el ser humano, como una categoría, a un lado, y todo lo demás -ya se llame ecosistema, naturaleza, o lo Real de la physis-, como otra categoría, al otro. El significante "naturaleza" - tan persistente en nuestra cultura pero tan ajena para la mayoría de culturas no-occidentales- es demasiado amplio, omniabarcante y abstracto, como para agrupar ahí todo aquello que no cabe dentro del orden humano. Somos proclives a seguir siendo presos del pensamiento cartesiano, cuando dividimos el mundo en diadas, pares, binomios, en los cuales "lo humano" o "la cultura" siempre ocupa uno de ellos, dejando a lo demás como otra polaridad. Aunque aparentemente la salida intermedia de Augusto Ángel Maya podría ser interesante al incluir la cultura como emergencia evolutiva de la naturaleza, seguimos dando pataleos tratando de lidiar con la otra diada propuesta: ecosistema/cultura. Cualquiera que sea la ruta, de alguna manera, seguimos pensando dónde poner el orden humano en algún tipo de dualismo.

En todo caso, así como el Monismo ontológico tiene sus dificultades al negar la diferencia, obviar el estatuto simbólico propio de "lo humano", y las condiciones termodinámicas de la vida en la Tierra, el Dualismo ontológico basado en la dialéctica y en la no-jerarquía, tiene el problema de seguir pensando "lo ambiental" desde dos polaridades. El universo es 
demasiado grande para contener la ontología de "lo no-humano" como un solo y único orden, y nosotros demasiado minúsculos en la inmensidad cósmica para pretender abarcar un enorme y gigantesco orden Ilamado "Cultura". Tendremos pues que disolver la dicotomía metafísica, pero también el monismo ontológico, y la dualidad dialéctica, y partir por otro camino, otra vía media.

Para ello necesitamos decir, de la mano de Deleuze (1973), que en realidad la oposición metafísica cartesiana no es entre lo Uno y lo Otro (lo humano vs. lo no-humano), sino, entre lo Uno y lo múltiple, es decir, "la oposición entre algo que puede ser afirmado como Uno, y algo que puede ser afirmado como múltiple". Sin embargo, aquí está el detalle: lo humano no puede ser categorizado como "lo Uno", dada la multiplicidad de mundos y cosmo-existencias (Blaser, 2009) que pueblan la tierra. No existe algo que podamos reducir a "lo Humano", en singular, como si pudiéramos agrupar la diversidad simbólica en una categoría universalizable como muy bien lo ha denunciado la antropología ambiental. Y dado que no podemos concebir "la naturaleza" como una sola dimensión aglutinada en un sólo dominio, en la medida en que por definición es múltiple, pierde sentido hacer cualquier tipo de oposición, así sea dialéctica, entre lo Uno y lo múltiple. No hay más relación hombre-naturaleza, y más bien podemos afirmar con el filósofo francés: "No hay nada que sea Uno, nada que sea múltiple, todo es multiplicidades".

La propuesta que hago en este artículo, siguiendo esta argumentación deleuziana, es salir por completo de los pares naturaleza y cultura, o ecosistema y cultura, y atender con radicalidad el fenómeno de las multiplicidades. Es decir, no partir de dos órdenes, de dos dimensiones, sino, desde el principio, de la multiplicidad que compone la vida. Esta alternativa, además, busca reactivar las subalteridades de la dominación patriarcal y ponerlas en primer plano como son el cuerpo, los afectos, las sensibilidades, y lo sagrado. El reto es hacer jugar las multiplicidades, sin querer borrar las diferencias, respetando la alteridad radical.

\section{MULTIPLICIDADES, ENMAÑARAMIENTOS, LÍNEAS, SENDEROS}

Las multiplicidades, han dicho, Deleuze y Guattari (2004), son rizomáticas, en el sentido de que son ramificaciones que van en todos los sentidos, y en donde cualquier punto puede conectarse con otro punto. En las multiplicidades no hay sujeto ni objeto, ni dualismos. Están en cambio compuestas de líneas, sin principio ni fin. Pues bien, para atender este concepto de las multiplicidades en la epistemología ambiental, considero que vale la pena estudiar el reciente trabajo que ha desarrollado el antropólogo inglés Tim Ingold (2015). Aunque no se referencie directamente en el trabajo deleuziano, pienso que su elaboración sobre las Líneas da una excelente primera imagen de lo que aquí quiero decir.

Según Ingold (2012) el ambiente podría verse como un enredo que incluye múltiples componentes tanto humanos como no-humanos. Para él, todas las criaturas que componen este enredo relacional son pasajeras que se acompañan en el mundo en el que todas están presentes, $y$, a través de sus acciones y movimientos, van creando las condiciones para que otras vivan. Lo que el antropólogo desea expresar, es que aquello que llamamos "ambiente", es una maraña de senderos o hilos entrelazados. Mucho más que una relación que emerge de la relación ecosistema-cultura -como piensa Augusto Ángel Maya-, el ambiente es un nudo de multiplicidades, una zona de enmarañamiento. Ingold (2012: 29) se apoya en el geógrafo sueco Torsten Hägerstrand 
(1976), para decir que al imaginar cada componente del ambiente "incluyendo humanos, plantas, animales y cosas, todos al mismo tiempo", en una trayectoria continua de movimiento, encontrándose con otras trayectorias, podemos ver cómo los diversos componentes se van entretejiendo.

En efecto, al ilustrar ese ambiente (Fig. 1), subraya Ingold (2015), bien podríamos comenzar dibujado una línea sinuosa en un papel con un color, asemejando una senda de movimiento de una criatura en un lugar. Pero dado que esa criatura no está sola, tendríamos que dibujar otros trazos de líneas, con diferentes colores cada una, que figurarían las sendas de otras expresiones de vida, quienes han llegado a ese mismo lugar por otros caminos. Si fuéramos añadiendo sendas a esa ilustración colorida, poco a poco, la imagen se iría volviendo cada vez más enrevesada. Las líneas irían entrelazándose, conformando un enredijo, un nudo. Pero las criaturas no se quedan ahí, sino que más bien siguen deambulando, andando, siguiendo sus caminos por otras rutas, y por tal razón el nudo que podemos dibujar es solo provisional. Tendríamos, entonces, que imaginar que las líneas van desenredándose hasta hacer otros nudos, para volverse a desenredar y conformar nuevos nudos, y así sucesivamente. Como ese nudo gordiano es el "ambiente", asegura Ingold (2012): una trama conformada por hilos de sendas de diversas criaturas y objetos que habitan un mismo lugar. Si lo viéramos desde adentro, dice Hägerstrand (1976), uno podría ver cómo las puntas de las trayectorias van siendo a veces empujadas hacia adelante, otras veces hacia atrás, yendo de un lado para otro, en todas las direcciones, sintiéndonos abrazados por el tapiz a medida que se mueven.

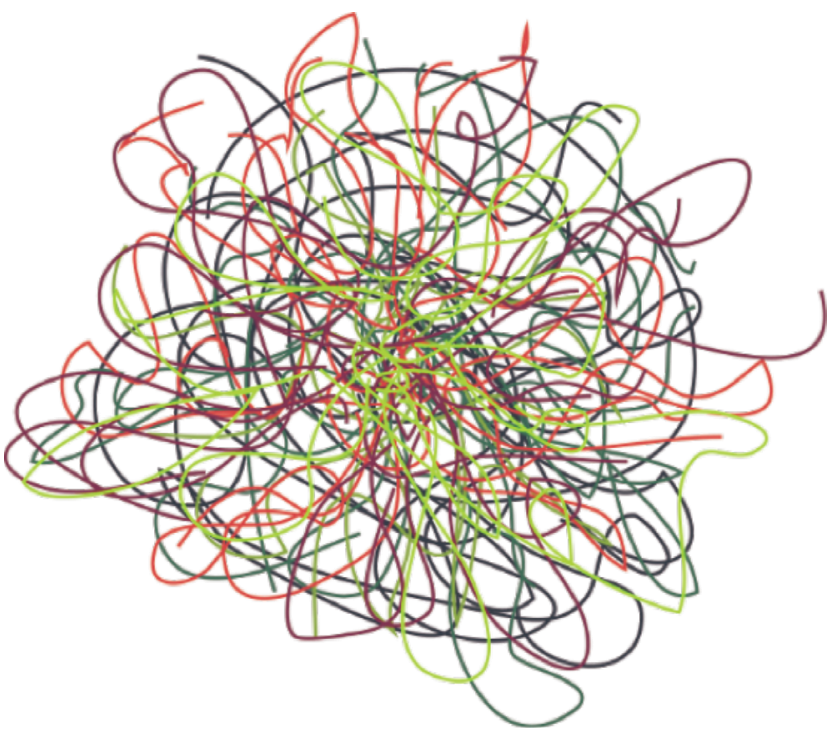

Figura 1. Enmarañamientos Fuente: Suministrada por el autor

Cada sendero dejado por cada criatura es un tipo de línea de vida. Entre los habitantes que formamos estos senderos están incontables tipos de seres: algunos reptando, otros caminando, unos volando, otros excavando, otros nadando, otros surcando con sus flagelos en el éter, otros moviéndose a través de sus rizomas y raíces por debajo de la tierra, otros en las escalas temporales de las formaciones geológicas, todos ellos juntos, habitando el mismo lugar. $Y$ en ese enmarañamiento, no hay fronteras, ni exteriores, ni podemos dibujar nada desde la teoría de conjuntos, pues la vida no puede contenerse. No puede cercarse. No hay entorno que nos rodee. No existen límites, ni fronteras, sino mallas de líneas en los que "distintos caminos se enmarañan por completo. Esta zona de maraña, esta malla de líneas entrecruzadas no tiene exterior ni interior, únicamente aperturas y vías" (Ingold, 2015: 148).

Visto en esa perspectiva, todos los componentes de esa gran trama, continúa Ingold (2012), no son seres, sino devenires: devenires pájaro, devenires herramientas, devenires plantas, devenires humanos, devenires bacteria, yendo de 
un lado para otro, formando un gran patrón de líneas entretejidas. No somos un orden escindido, tratando de hacer empalmes, sino desde siempre seres habitando junto a otros. Difícilmente podemos decir dónde termina una persona y dónde empieza su ambiente. Estamos tan enmarañados en el tapiz de los senderos, que no podemos pensarnos desde fuera, intentando acceder a "la naturaleza" - con lo que ello tiene de asociado a la exterioridad-, y menos pensar lo no-humano como "el entorno" o "el medio". En el rizoma de la vida cada línea está siempre moviéndose, entrelazándose con otras líneas que también se mueven, deshilachándose aquí e hilachándose allá, tejiendo en conjunto la gran trama de la vida.

\section{CUERPOS ENTRE CUERPOS, ENCUENTROS}

Esta noción de enredos y enmarañamientos en constante movimiento da una primera imagen no completamente satisfactoria, pero sí introductoria, para crear un tipo de epistemología ambiental. De mi parte, e inspirándome en Spinoza, en el pensamiento ambiental latinoamericano de Patricia Noguera y José Luis Grosso, en la fenomenóloga mexicana Emma León y en el neurobiólogo Francisco Varela, quiero seguir el planteamiento de Ingold, pero desde la noción de Cuerpos entre Cuerpos.

Para empezar tendríamos que preguntar: ¿Qué es aquello que sigue senderos, caminos y rutas? ¿Qué es eso que se enreda y desenreda? Esas preguntas nos Ilevan inmediatamente a la respuesta de que quien se mueve y deambula, quien construye el ambiente como zona de enmarañamiento, es el cuerpo. Hablo de los cuerpos-piedras, los cuerpos-agua, los cuerpos-aire, los cuerpos-fuego, los cuerposplantas, los cuerpos-animales, los cuerposhumanos. Sin embargo, aún tendríamos que precisar ¿qué es aquello que llamamos "cuerpo"? Para contestar ese cuestionamiento bien vale la pena remitirse al examen del cuerpo humano y la pregunta sobre si el cuerpo es nuestro "yo", tal como lo preguntan los textos budistas del Abhidharma.

Siguiendo la explicación de Varela, Thompson y Rosch (1997: 89), tratamos nuestro cuerpo como si fuera nuestro "yo". El cuerpo es el lugar donde están los sentidos, percibimos el mundo desde el cuerpo "¿Pero de veras creemos que el cuerpo equivale al yo?". Pensemos cómo la configuración de nuestro cuerpo cambia permanentemente, las células están en constante proceso de cambio, de modo que un organismo no es el mismo después de unos cuantos meses. Lo anterior significa que una persona nunca es idéntica a sí misma. Después de unos meses de renovación celular cambian sus componentes, y en tal sentido ya no es el mismo cuerpo, pero, en otro sentido, esa persona tampoco es completamente distinta, en cuanto mantiene su estructura y su patrón organizativo.

Examinemos la cantidad de pequeños cuerpos que alberga nuestro cuerpo. Como se ha descrito, en él habitan unos 48 billones de bacterias, 60 billones de virus, varios miles de millones de hongos y otros millones de ácaros, los cuales reunidos, resultan mucho más numerosos que las células del propio cuerpo. Quizá podríamos decir que "tengo un cuerpo que me pertenece", pero podríamos decir que ¿esos cuerpos-microbios que viven en mi cuerpo me pertenecen? (Varela, Thompson y Rosch, 1997).

Pensemos ahora en el agua. Sabemos, que nuestro cuerpo está conformado por un $70 \%$ de agua, pero ¿esa agua hace parte de mi "yo"? La ciencia nos ha contado que cada molécula de agua ha existido durante miles de millones de años. Ella vino a la Tierra con asteroides y cometas, y desde ahí ha estado circulando a 
través de rocas, animales y plantas. Antes de que esa agua constituyera la mayor parte de mi cuerpo, estuvo dentro de océanos, lluvias, congelada en los casquetes polares, y fue parte de bacterias y dinosaurios (Jha, 2015). Esa agua no quedará quieta, sino que seguirá circulando una vez abandone el cuerpo, y siga su deambular, sus rutas de movimiento.

Por cualquiera de las vías ${ }^{5}$, no hay un fundamento para decir que exista algo, en sí mismo, que pueda llamarse, de manera delimitada como "Cuerpo", en la medida en la que no podemos imaginar ningún cuerpo separado de su exterior por la frontera de su piel, o de sus escamas, corteza o caparazón. En realidad ¿dónde empieza y termina un cuerpo? ¿Podría pensarse un cuerpo al margen de lo que habita y lo que lo habita? ¿Existe un cuerpo yoico? El cuerpo quizá debamos definirlo por el conjunto de relaciones que lo componen, no por una esencia unitaria, sino por la dinámica de relaciones corpóreas y extra-corpóreas que lo conforman. De hecho quizá la palabra cuerpo, no sea un sustantivo, sino un verbo, un acto. No somos cuerpo, sino que en todo momento estamos en proceso de corporizarnos, de inter-encarnarnos a través de los distintos encuentros (León, 2017). La configuración de aquello que erróneamente llamamos "yo" no es más que una serie de encuentros, de senderos, como diría Ingold, de cuerpos deambulando que se encuentran con otros cuerpos, pero que también se desencuentran, para seguir otras rutas en la que se encontrarán con otros cuerpos.

El filósofo budista Juan Arnau (2017:111) nos recuerda cómo Berkeley "aseguraba que el sabor de una manzana no reside en la manzana

${ }^{5}$ De los libros del Abhidharma solo hemos explorado el primero de ellos que es el del cuerpo. El resto constituye los agregados mentales, en los cuales, según la doctrina, no existe tampoco ningún fundamento para encontrar un "yo". misma, ni tampoco en la persona que lo saborea, sino en el encuentro entre ambas". La manzana es el resultado de un flujo de encuentros, como la semilla y la lluvia, los microorganismos del suelo y el árbol, la cosecha y la mano del campesino, así como la persona es fruto del encuentro entre sus padres, y sus gametos, así como de una multitud de encuentros en su historia de vida. La larga trayectoria de la manzana, diría José Luis Grosso ${ }^{6}$, es la que nos toca, la que allega a nuestra lengua. El placer del sabor de la manzana es el placer de la relación, no en lo que está aquí adentromis papilas gustativas-; no en lo que está afuera - la piel de la manzana y su jugo-, sino el encuentro entre ambas superficies, una relación entre cuerpos. La manzana me toca, yo la toco. Estamos en contacto cotidiano con los seres del mundo, por eso dice Arnau (2017: 112), la persona y la manzana son encuentros, "en una cadena cuyo origen no podemos localizar". Somos Cuerpos entre Cuerpos encontrándonos. Encuentros energéticos, químicos, sensibles a distintas escalas: desde la escala de la manzana y la boca de la persona, pasando por las partículas subatómicas que le subyacen, hasta las que acontecen a la escala de las constelaciones. Pero además de escalas diferenciadas, somos encuentros entre distintas velocidades: desde el vertiginoso movimiento de los electrones, o el acelerado ritmo del crecimiento de bacterias, hasta el lento movimiento de un árbol a través del suelo, o las lentísimas celeridades de las piedras. Somos entrelazamientos entre diversos tipos de cuerpos, entrecruzándonos por senderos dinámicos, en una relación entre escalas, velocidades y lentitudes.

Nuestra existencia es un inter-existir, un serestando, entre-estando, fluyendo, encarnándonos, creando estados que se desvanecen, para

\footnotetext{
${ }^{6}$ La potencia de la voz y el pensamiento del filósofo argentino José Luis Grosso, me animó por primera vez, a pensar "lo ambiental" como un asunto de Cuerpos entre Cuerpos.
} 
dar pie a nuevos estados. Con nuestros actos y los actos de otros, con nuestras sensibilidades y las sensibilidades de otros, estamos "acá", transformándonos, intercambiando, trenzándonos, entre las distintas expresiones de vida, interactuando al interior de un universo sintiente que nos abarca. Spinoza enseñó que somos expresiones de vida, "vida dentro de la vida", como diría Emma León (2017), tutelados por las interacciones de nuestros enredos relacionales. Lo que somos depende de lo que logra enmarañarse, de las composiciones de muchos y diversos organismos, cada uno de los cuales, está compuesto de otros organismos. Como muñecas rusas, nuestra vida solo es posible gracias a las vidas que llevamos adentro (Haskel, 2012). No somos, sino que inter-somos, expresaría el maestro budista Titch Nath Hann (1975).

Cuerpos entre Cuerpos da cuenta de la interencarnación, o la co-corporización que surge del encuentro entre una multiplicidad de fuerzas, energías, sensibilidades, humores, afectos que interactúan dinámicamente (León, 2017). Esta visión adopta una vía intermedia que toma en serio las interdependencias del pensamiento spinoziano, y la crítica al borramiento de la diferencia. No hay monismo, entendido como totalización, sino encuentros entre alteridades radicales. Diferencia ontológica. Cada cuerpo contenido en las diversas formas corpóreas, ya sea de carne y hueso, espinas y escamas, corteza y madera, interactúan diferenciadamente con los cuerpos con los cuales se encuentran. La alteridad radical y la renuncia a todo monismo totalizante, radica en las especificidades morfológicas, históricas, filogenéticas, y en las posibilidades estructurales de cada tipo de cuerpo.

Entonces podemos decir que la diferencia radical comienza con el cuerpo. Pues no es igual tener "manos que garras, pulmones en lugar de branquias, brazos en vez de alas, piel que escamas" como asegura Emma León (2017:
56). Cada quien experiencia el mundo sensible a su modo, y vive sus procesos de co-corporización en el estar-siendo-entre-otros-cuerpos. A veces amalgamándose y fusionándose, a veces separándose y siguiendo nuevos senderos. Somos-siendo gracias al movimiento, al cambio, a la impermanencia, gracias a los fenómenos de entrelazamiento entre materia y energía. Los cuerpos, sus fluidos, sus fuerzas térmicas, sus energías vitales inundan y se transmutan con otros fluidos, otras fuerzas térmicas, otras energías vitales. La vida dentro de la vida, radica justamente en la alteridad radical que caracteriza los encuentros entre los distintos cuerpos (León, 2017).

Sin embargo, es necesario señalar que los encuentros no son azarosos, como da a entender Tim Ingold con su imagen del nudo. Ellos obedecen a un patrón auto-organizativo que explica algunas de las regularidades que vemos en nuestro planeta, y que se amalgaman creando las proporciones y la belleza del flujo de la vida. Las matemáticas de Turing (1999), han mostrado cómo las rayas de una cebra, las manchas del jaguar, la disposición de los dedos en la mano, la espiral del caracol, la disposición de las plumas de las aves, la ubicación espacial de los predadores y presas, las circunvoluciones del cerebro, o las formas de la vegetación, obedecen a una interacción particular de moléculas que siguen combinaciones reiterativas. En otras palabras: las moléculas se auto-organizan y retroalimentan de manera espontánea siguiendo un repetitivo patrón biológico. Las líneas dejadas por los senderos de Ingold, más que enmarañamientos, son patrones auto-organizados, figuras repetitivas, que explican el parecido entre la piel de un jaguar y formaciones vegetativas en áreas áridas; las manchas de la cebra y las crestas que se forman en las dunas de la arena; o el coral marino y los mosaicos de las selvas tropicales (Fig. 2). 


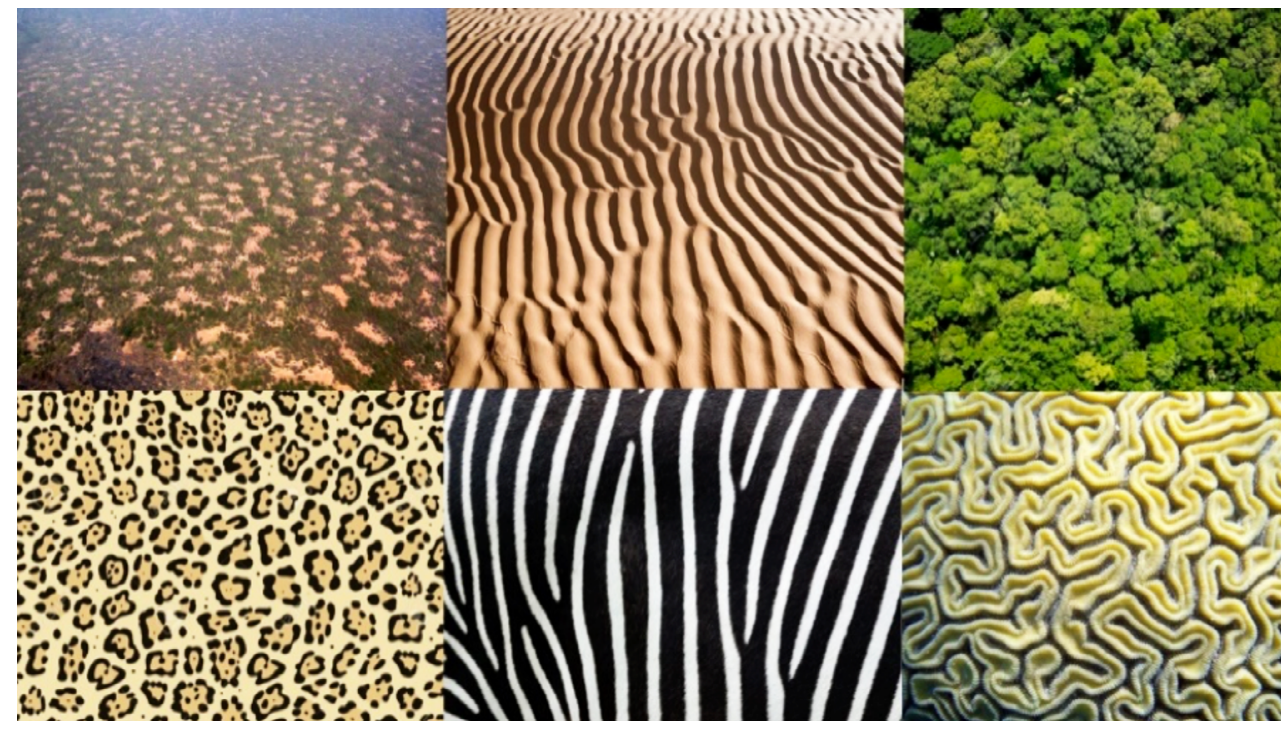

Figura 2: Patrones de Turing y estéticas auto-organizadas.

Fuente: Barbier, N. (01-12-2003), Delstudio (s.f.), Limpakdeesavasd, R. (s.f.),

Olkita (s.f.),Blog:Fractal (s.f.), Monib, M. (s.f.).

Los encuentros, mucho más que encuentros fortuitos y desorganizados, siguen una lógica estética. Se trata de muchos procesos que se encuentran con otros procesos diferentes, que al ligarse van componiendo un ballet, una danza de agrupaciones y reagrupaciones que siguen una sucesión necesaria (Hägerstrand, 1976). Precisamente gracias a que los distintos devenires no se encuentran desorganizadamente, sino que siguen los patrones que identificamos en las distintas formaciones biológicas y geológicas, es que podemos percibir la belleza de nuestro esplendoroso planeta vivo. El ambiente es entonces, un proceso de encuentros, de entrelazamientos, sí -convenimos con Ingold-, pero es un proceso auto-organizado y dinámico en largas trayectorias co-evolutivas, por las cuales se van formando simetrías, proporcionalidades, y formas repetitivas en lugares insospechados. Así es que consideramos hermosos todos los patrones biológicos: la simetría en las alas de la mariposa, el equilibrio en el rostro de los animales y la combinación de los colores de las aves. La armonía que brilla de las proporciones que surgen en la trama de la vida.
Esta forma de pensar los misterios relacionales de nuestra Madre Tierra, contrastan con la extraña noción moderna de "naturaleza" entendida como telón de fondo o exterioridad. Somos más bien senderos, agregados de movimientos, que siguen patrones en el trasegar de los elementos y sus ciclos, del entrecruzamiento de multiplicidades de devenires. La clave es que no partamos de un mundo desligado para ir luego a su encuentro, sino entendernos desde el principio "ya siempre habitando". Cuando hablamos de ser humano y naturaleza, pareciese que las personas estuviéramos en un lado y la naturaleza en otro lado. Pero la multiplicidad que habitamos y nos habita no es un enfrente de las personas, no es un objeto exterior. No existen seres humanos y además naturaleza (Heidegger, 1994). Estamos "aquí no más" (Kusch, 1976) junto a otros, recibiendo las sensaciones y potencias de otros cuerpos con los cuales nos encontramos.

En este magma descentrado, lo que hay es una inconsistencia ontológica: no hay centro donde señalar con el dedo y decir "ahí está". Parece que se tratase de una ontología del cuerpo, pero 
tampoco hay fundamento en algo en sí mismo que podamos llamar, delimitadamente como "Cuerpo". Es una ontología desparramada, vacía de todo centro, que se distribuye por el territorio de los Cuerpos entre otros Cuerpos. La epistemología ambiental entiende que ningún cuerpo puede existir sin los otros, pues cada uno de ellos adquiere sus propiedades como resultado de sus interacciones con los demás. Sin embargo, existe también una paradoja, porque también es una ontología en donde no hay fusión y pérdida de la diferencia, como bien advierte Plumwood. Pues cada cuerpo, al mismo tiempo que se mantiene unido a otros, se distingue como una unidad diferenciada. Es una suerte de dialéctica entre continuidad y diferencia, en la que existe una unión indisoluble entre diversos modos de vida, pero justamente ese enlace vital de co-determinaciones es el que permite a cada organismo mantener su propia individualidad (Varela, 2000).

El problema epistémico de aquello que llamamos "lo ambiental" consiste en entender que no existe separación, divorcio, sino enmarañamiento dinámico, preñez de proliferaciones que siguen patrones estéticos, pero al mismo tiempo, comprender que entre los múltiples somos diferentes. Esa diversidad de encuentros explica la vida. Habitamos con otras alteridades, estando inter-penetrados, implicados, involucrados, en la espesa urdimbre de la vida. Por eso somos vida dentro de la vida, una forma de vida que mantiene su propia estructura y especificaciones, que no se disuelve en un todo mayor, pero que tampoco puede imaginarse al margen de lo demás.

\section{LA ALTERIDAD HUMANA

EN EL TEJIDO DE LA VIDA

La antropología de Geertz (1991) ha dicho que los seres humanos somos un tipo singular de criatura que teje su vida gracias a las formaciones simbólicas. Pero ello hay que entenderlo como una cualidad definitoria de nuestra especie en los senderos que conformamos junto a otros. Nuestro cuerpo en sus particulares formas del "estar", afecta y es afectado por el contacto con las otras manifestaciones de vida del mundo. Pero esas afecciones, como tan bien explica Ema León (2017) se funden y confunden entre energías químicas, térmicas, eléctricas y procesos mentales. Los encuentros nos afectan, pero de una manera amalgamada, en la que se fusionan el contacto, la percepción, la conciencia, la inconsciencia, las apetencias, el deseo y los sentimientos, los cuales se activan durante el intercambio con otras encarnaciones, otras criaturas y otras fuerzas. Esas afecciones las vamos integrando en nuestro cuerpo, y, todas, en conjunto, repercuten en un imbricado tapiz de sensibilidades entretejidas.

A ese magma de afectos, que unas veces se traducen en alegría, ternura, amor, placer, o compasión, y en otras, en repulsión, hostilidad, odio, envidia, desprecio, indignación, ira, angustia, los dotamos de significación. Se encarnan en nosotros y le imprimimos sentido a través de las palabras, el pensamiento y la razón. Es el modo como vamos organizándolas en el lenguaje. Nuestro territorio-cuerpo es una multiplicidad de materiales, afectos y contenidos cohesionados que nos con-mueven, que crean erupciones senti-mentales -según el agudo concepto de León- y que están en constante renovación. Sus posibilidades están asociadas a nuestra larga historia filogenética y social, y por tanto difieren de otro tipo de trayectorias filogenéticas y sociales (León, 2017).

El devenir humano colectivo, le da forma y moldea ese maremágnum de afectos mediante su complejo cultural. Nos valemos de nuestras capacidades racionales y de "comprensión para darle sentido o propósito a nuestros estados anímicos y sentires" (León, 2017:152). A nuestras 
perturbaciones y reacciones emocionales que surgen como resultado del Estar entre otros Cuerpos, le damos forma en el lenguaje. No tenemos más guarida que lenguajear el caudal de fuerzas que se encuentran unas a otras, según nuestras posibilidades culturales.

Para comprender mejor este entrelazamiento entre los estados mentales, los cuerpos con los que interactuamos y las formas lingüísticas, es útil traer a cuenta el ejemplo de la percepción del color. El neurobiólogo Francisco Varela (2000), ha explicado cómo la percepción no consiste en "recuperar" la "información" que llega desde afuera de manera precisa -como lo concibe la epistemología cartesiana-. El color es en realidad una especie de encuentro, un diálogo filogenético que activa un modo de asociación, de muchos otros que pueden ser posibles, según la historia co-evolutiva de cada organismo. Varela (2000) señala cómo la luz y el reflejo crean una perturbación que activa a las redes neuronales para constituir correlaciones senso-motoras. Es gracias a la historia de cada organismo - pensemos la diferencia en los mundos de color entre un ser humano y los de una mosca, por ejemplo-, que un modo de asociación, o encuentro entre cuerpos, se hace regular y repetitivo. Así es que por facilidad lingüística podemos imaginar que los colores corresponden o representan algún aspecto del mundo, cuando en realidad son la emergencia de un encuentro entre un mundo exterior al organismo, que gatilla otros encuentros internos, como son las operaciones neuronales cooperativas (Varela, 2000).

Sin embargo, las capacidades del cuerpo humano, y su habilidad cognitiva de significar el mundo, no es un universal pan-humano. Aunque si bien hay regularidades en la percepción de colores propios de la especie, existen percepciones cromáticas específicas a las lenguas de cada cultura. No es lo mismo la percepción del "amarillo", "azul", "rojo", "negro" o "blanco" en inglés, que la percepción de esos mismos "colores" en el dani de Nueva Guinea - un idioma que tiene sólo dos términos para los colores básicos-; o la percepción del "verde" y el "azul" del español, que la del tarahumara -lengua que sólo tiene un término para el verde y el azul-. En gran medida la memoria cromática está en función de la designación lingüística propia de cada cultura. Ese ejemplo, da cuenta, de cómo la percepción es en realidad un encuentro que depende de nuestra historia biológica y cultural, de la combinación entre la larga trayectoria co-evolutiva propia de cada especie, y la trayectoria social específica de cada cultura (Varela, Thompson y Rosch, 1997).

Los procesos de apropiación del mundo están regidos por complejas vías, a diferentes escalas, en donde se conjugan aspectos propios de la biología y de la fisiología de cada tipo de organismo, con el lenguaje y los mundos culturalmente diferenciados. Habitar escapa a todo tipo de dicotomía entre lo racional y lo afectivo, la mente y el resto del cuerpo, el consiente y el inconsciente, la naturaleza y la cultura. Estamos intercambiando entre Cuerpos, en un campo de fuerzas donde se diluye todo tipo de dualismos. Somos cuerpos simbólico-biótico-afectivos, en la terminología de Patricia Noguera (2012), es decir cuerpos en los cuales se anidan complejas elaboraciones senti-mentales infiltradas por enmarañamientos lingüísticos sociales y por formas colectivas de enunciación. Entrelazamientos en el que se enmaraña el fuego, el aire, la tierra y el agua, el polvo estelar de las constelaciones, con los humores y temperancias, las palabras y los afectos, en un patrón de auto-organización dinámico e impermanente.

$\mathrm{Ni}$ el ser humano, ni ninguna otra criatura, está encerrado en sí mismo, aprisionado en la cápsula de su piel; más bien somos pasajeros 
de un viaje que se hace junto a otros, que parece iniciar en el momento de nuestro nacimiento y acabar en el momento de la muerte, pero que más bien es un viaje mucho más largo hecho de constantes transformaciones, de trayectorias impensadas, por las cuales hemos estado deambulando a través de distintas escalas y tiempos. Oponemos los conceptos de la vida y de la muerte, en otro dualismo, cuando en realidad son parte del mismo proceso del devenir multiplicidades, de ser entes en constante transformación. La muerte parece el fin de la vida, que ocurre sin más, como un interruptor que de repente se apaga. Pero la muerte es otro proceso de continuación del estar acá, de ser un modo de emergencia y manifestación de la inmanencia de la vida, de obedecer a los procesos del reciclaje constante de la materia, transformación de energía y entropía del universo. Sin embargo, en cuanto seres simbólico-bióticoafectivos debemos darle un tipo de sentido a aquello que llamamos muerte y vida a través del lenguaje. La primera, como modernos, la historiamos a través de la jerga científica; la segunda, más inasible, más inescrutable, la simbolizamos a través de la invocación de lo sagrado y lo divino. En cualquiera de sus formas estamos historiando la angustia, la incertidumbre, el temor, y "la pregunta por el sentido del ser" -en términos heideggerianos-, a través del lenguaje. Somos pues agregados indisociables entre la materia y el símbolo: un devenir muy transitorio y corto, que experiencia su breve estado "individual" a través de un formato lingüístico.

\section{EPISTEMOESTESIS Y ETHOS AMBIENTAL}

La epistemología ambiental más que un modo de comprender la forma como el pensamiento y el corazón de una cultura presuntuosa y confundida se disoció y extravío de la tierra que somos, es una ontología de la vida (Leff, 2018), que intenta reintegrar el pensamiento de nuestra estancia terrestre a la majestuosidad del universo. Para ello trata de romper todo molde antropocéntrico para crear otra forma de acoplamiento simbólico, que haga parte de un nuevo ethos ambiental. Más que una epistemología, esta forma de entender nuestras formas del Estar y el Habitar, es una epistemoestésis - según como lo ha venido trabajando la filósofa Patricia Noguera-, remplazando el sufijo "logos" por "estésis", entendido como la intensidad de las percepciones de los sentidos. En ella, como hemos visto, hay una disolución del sujeto y el objeto modernos, evitando partir de falsas dicotomías, y optando, en cambio, por iniciar con el propio cuerpo y la forma como somos afectados por los distintos encuentros. Acá las discusiones sobre los monismos o dualismos dejan de tener mucho sentido, dando apertura al involucramiento, al estar-siendo acá adentro, entre multiplicidades.

La ética que surge de esta epistemo-estésis ambiental, de esta ontología de la vida, no es una moral del "deber ser". La moral es el sistema del juicio, que funciona a través de los valores, de los preceptos y los mandatos. No es el punto de vista del Estar entre cuerpos. Lao Tse lo veía muy bien al sentenciar: "cuando desaparece el Tao aparece la moral", porque cuando se desvanece el sentido de pertenencia a un todo abarcante, surge la necesidad de decirle a los demás lo "que deben" hacer; emerge la obligación y el enjuiciamiento racional. La ética ambiental, en cambio, parte desde una ontología del Estar, la ontología del habitar: "está más cerca a la sabiduría que a la razón" (Varela, 1992: 13). ¿Qué tenemos que decirles a los demás? ¿Que no talen bosques? ¿Que no contaminen? ¿Que cuiden el agua? Nada de ello. No tenemos ningún tipo de dictados, nada que entendamos mejor, ninguna clase de superioridad moral. Nosotros partimos de otra geografía, de la geo-grafía del contacto (Noguera, 2012). 
El ethos ambiental parte del contacto con los seres del mundo y la consciencia de lo que implica ese contacto. Comienza con el involucramiento del propio cuerpo, de la confrontación inmediata con situaciones de las que nos hacemos conscientes (Varela, 1992), como cuando prestamos atención al trasegar de la manzana, y sus senderos recorridos hasta tocar la superficie de nuestra lengua. De esa forma nos vamos haciendo conscientes de los encuentros, para concluir entendiéndonos como inter-corporalidades. No es una epistemología de la metafísica trascendental, en la que partimos de un mundo externo sobre el cual llegamos con juicios racionales, sino que lo hacemos incluyendo nuestra participación, nuestro universo sensible; involucrando nuestro propio cuerpo. No se trata de buscar culpas, ni "sentirnos mal". Todo lo contrario: se trata de apreciarnos implicados en los placeres del "Estar"; sabernos inter-penetrados en cada respiración con los cuerpos, y reconocer lo placentero que es la relación con los seres del mundo (Grosso, 2012).

Hacerse sensible a la fenomenología de los encuentros implica reconocer cuando "me siento bien", cuando el encuentro con lo otro me da alegría, en la medida en la que los otros cuerpos se combinan con mi cuerpo en proporciones y condiciones favorables. Cuando ocurre que la potencia de un cuerpo, su fuerza, su energía, su magnetismo, se mezcla con el mío de forma tal que experimento placer. Pero también, cuando los encuentros me generan experiencias desagradables, cuando el encuentro entre dos cuerpos se convienen de una forma tal en la que me siento mal, en la que siento tristeza, indignación, ira (Deleuze, 1978). Ambas experiencias, son experiencias sensibles, experiencias que me afectan, y potencian un determinado modo de actuar. Quizá así podamos sentir alegría con los encuentros entre mi cuerpo y los cuerpos de un lugar sobreabundante de relaciones, y tristeza ante la devastación de la vida.

El entrelazamiento inter-corpóreo genera afecciones. "Somos afectados", lo cual quiere decir que nuestro cuerpo tiene un efecto por la acción de otro cuerpo. Esto por supuesto, no puede hacerse a distancia: implica un contacto, una combinación entretejida de cuerpos. Un contacto que afecta a un cuerpo, y ese a otro, y así sucesivamente, creando una mezcla de cuerpos. Sin embargo, sigue y seguirá siendo enigmático y misterioso, cómo se hacen presentes las cosas en la experiencia, y cómo cobran vida las afecciones y los procesos mentales. No tenemos idea de cómo se mezclan los cuerpos. Solo nos queda la sensibilidad para saberlo: conocer los otros cuerpos por las afecciones que ellos producen sobre nuestro cuerpo. Solo puedo conocer los nudos, los senderos entretejidos, las mallas de cuerpos, y a mí mismo, por la acción que ejercen otros cuerpos sobre el mío. No puedo conocer al sol mismo, más allá que por su efecto sobre mi cuerpo. Es por la naturaleza del encuentro, como la relación del cuerpo que me modifica, y actúa sobre mí; por la forma en que sus rayos se fusionan con las relaciones características de mi propio cuerpo.

El ethos ambiental es pues una epistemo-estésis. Una manera en las que las sensibilidades, lo sintiente, lo sentido, la piel, los contactos entran en primera escena (Noguera, 2004). Una ética que comienza siempre desde el cuerpo. Seguimos aquí la ética spinoziana, la cual no se basa en valores y juicios morales, sino una ética activa que pregunta ¿qué es lo que puede un cuerpo? Es decir, no preguntamos ¿qué debes hacer? sino ¿de qué eres capaz? ¿qué puedes? No es un interrogante para un cuerpo abstracto, sino una pregunta dirigida 
a mí: ¿qué es lo que yo puedo? ¿de qué experiencia soy capaz? ¿qué puedo hacer en virtud de mi potencia? (Deleuze, 1978). Esta ética es activa, nos habla del poder, de las cosas de las que somos capaces al reconocernos como Cuerpos entre Cuerpos.

Lo anterior, por supuesto que no es fácil. Como dice Francisco Varela (1992: 42): "tenemos el mundo en el que vivimos tan al alcance de la mano que no ponderamos lo que es ni cómo vivimos en él". Los encuentros cotidianos, con los seres del mundo con los cuales nos interpenetramos, parecen tan dados, que no solo no los vemos, sino que tampoco vemos que no los vemos, asegura el mismo Varela. El reto entonces implica hallar distintas puertas para ejercitar la sensibilidad, hasta descubrir que somos Cuerpos entre Cuerpos, resultado de múltiples encuentros, inter-seres entreestando. No hay otra salida que apelar a la sabiduría y al poder de nuestro cuerpo, para co-construir entre todos este otro ethos, si lo que queremos es dar un giro al colapso civilizatorio al cual estamos encauzados. Las dicotomías no tienen cabida en dicho propósito. Lo que requerimos es de una epistemo-estésis que hagan emerger otro tipo de sensibilidad, una sensibilidad que nos potencie a reinscribir nuestro hacer en las condiciones que hacen posible la vida en la Tierra. Las posibilidades son insospechadas, pues en realidad no sabemos lo que puede un cuerpo, o mejor aún, todo el poder que tiene cuando se sabe como un cuerpo que habita entre otros cuerpos.

\section{LITERATURA CITADA}

Ángel, A. (1996). El reto de la vida. Ecosistema y cultura. Bogotá: Ecofondo.

Arnau, J. (2017). Budismo esencial. Madrid: Alianza Editorial.

Blaser, M. (2009). Political ontology: cultural studies without 'cultures'? Cultural Studies, 23(56),873-896. https://doi.org/10.1080/09502380903208023
Bookchin, M. (1990). The Philosophy of Social Ecology Essays on Dialectical Naturalism. Montreal: Black Rose Books.

Capra, F. (1998). La trama de la vida. Barcelona: Editorial Anagrama.

De Castro, E. V. (1998). Cosmological deixis and Amerindian perspectivism. Journal of the Royal Anthropological Institute, 469-488. https://doi.org/10.2307/3034157

Deleuze, G. (1973). "Dualismo, monismo y multiplicidades". Curso del 26/03/73.

Deleuze, G. (1978). Sur Spinoza. Curso del 24/01/1978.

Deleuze, G. (1980). Sur Spinoza. Curso del 25/11/1980.

Deleuze, G. y Guattari, F. (2004). Mil mesetas. Capitalismo y esquizofrenia. Valencia: Pre-Textos.

Descola, P. y Pálsson, G. (ed.) (2001). Naturaleza y cultura. Perspectivas antropológicas. México D.F.: Siglo XXI Editores.

Edgar, M. (1986). El Método, La naturaleza de la naturaleza. Madrid: Ediciones Cátedra.

Escobar, A. (2013). "En el trasfondo de nuestra cultura: la tradición racionalista y el problema del dualismo ontológico". Tabula Rasa (18), 15-42.

Fox, W. (1984). Deep ecology: a new philosophy of our time? The ecologist, 14(5/6), 194-200.

Geertz, C. (1991). La interpretación de las culturas. Barcelona: Editorial Gedisa.

Grosso, J. L. (2012). Del socioanálisis a la semiopraxis de la gestión social del conocimiento: contranarrativas en la telaraña global. Popayán: Universidad del Cauca Colombia.

Hägerstrand, T. (1976). "Geography and the study of the interaction between nature and society". Geoforum (7), 329-334.

Haskell, D. G. (2012). En un metro de bosque, un año observando la naturaleza. Madrid: Turner.

Heidegger, M. (1994). "Construir, habitar, pensar". En Conferencias y Artículos. Barcelona: Ediciones del Serbal.

Heidegger, M. (1996). "La época de la imagen del mundo". En Caminos del bosque. Madrid: Alianza.

Ingold, T. (2012). Ambientes para la vida. Montevideo: Ediciones Trilce. 
Ingold, T. (2015). Líneas: una breve historia. BarceIona: Editorial Gedisa.

Jha, A. (2015). The water book. London: Hachette UK.

Johnston, A. (2010). "Fantasmas del pasado de las sustancias: Schelling, Lacan y la desnaturalización de la naturaleza". En Žižek, S. (comp.). Lacan. Los interlocutores mudos. Madrid: Akal.

Kusch, R. (1976). Geocultura del hombre americano. Buenos Aires: Fernando Garcia Cambeiro.

Leff, E. (2004). Racionalidad ambiental. La reapropiación social de la naturaleza. México D.F.: Siglo XXI Editores.

Leff, E. (2014). La apuesta por la vida. Imaginación sociológica e imaginarios sociales en los territorios ambientales del sur. México D.F.: Siglo XXI Editores.

Leff, E. (2018). El fuego de la vida. Heidegger frente a la cuestión ambiental. México D.F.: Siglo XXI Editores.

León, E. (2017). Vivir queriendo: ensayos sobre las fuentes animadas de la afectividad. Madrid: Sequitur.

López-Intzín, J. (2015). "Ich'el-ta-muk': la trama en la construcción del Lekil-kuxlejal. Hacia una hermeneusis intercultural o visibilización de saberes desde la matricialidad del sentipensar-sentisaber tzeltal" en Leyva, Xochitl y Köhler, Axel (coord.) Prácticas otras de conocimiento (s). Entre crisis, entre guerras. Tomo I. Guadalajara: Editorial Casa del Mago.

Lovelock, J. (2007). La venganza de la tierra. México D.F.: Editorial Planeta.

Naess, A. (1980). "Environmental ethics and Spinoza's ethics". Inquiry (23), 313-25.
Naess, A. (2007). The selected works of Arne Naess (Vol. 1). Berlin: Springer Science \& Business Media.

Nāgārjuna. (2004). Fundamentos de la vía media. Traducción directa del sánscrito a cargo de de Arnau, J. Madrid: Editorial Siruela.

Nhat Hanh, T. (1975). The miracle of mindfulness. Boston: Beacon press.

Noguera, A. P. (2012). Cuerpo-Tierra. El Enigma, El Habitar, La vida. Potencias de un Pensamiento Ambiental en clave del Reencantamiento del Mundo. Madrid: Editorial Académica Española.

Noguera, A.P. (2004). El reencantamiento del mundo. México D.F.: PNUMA-Universidad Nacional de Colombia.

Plumwood, V. (2002). Feminism and the Mastery of Nature. London: Routledge.

Plumwood, V. (2005). Environmental culture: The ecological crisis of reason. London: Routledge.

Ruiz, I. (2018). Pensar la naturaleza con Lacan: significante, sujeto escindido y objeto a. Tópicos del Seminario (39), 125-145.

Spinoza, B. (2011). Ética. Madrid: Alianza Editorial.

Turing, A. M. (1990). The chemical basis of morphogenesis. Bulletin of mathematical biology 52(12), 153-197.

Varela, F. (1992). La habilidad ética. Barcelona: Debate.

Varela, F. (2000). El fenómeno de la vida: Santiago de Chile: Dolmen Ediciones.

Varela, F., Thompson, E. y Rosch, E. (1997). De cuerpo presente. Las ciencias cognitivas y la experiencia humana. Barcelona: Editorial Gedisa. 